\title{
The Design of Object Tracking System in Robot Vision Using Circle Hough Transform and CAMSHIFT Methods
}

\author{
Muhammad Luqman Bukhori ${ }^{1}$, Aris Triwiyatno ${ }^{2}$, R. Rizal Isnanto ${ }^{3}$ \\ \{mluqmanbukhori@student.undip.ac.id ${ }^{1}$, aristriwiyatno@undip.ac.id ${ }^{2}$,rizal_isnanto@yahoo.com ${ }^{3}$ \} \\ Dept. of Electrical Engineering, Diponegoro University ${ }^{12}$, Dept. of Computer Engineering, \\ Diponegoro University ${ }^{3}$
}

\begin{abstract}
Robot vision is a combination of cameras with computational algorithms that are used to manipulate the visual data in real time. The visual data which are obtained will be used as a reference for doing detection and tracking of the object. In this study, it needs a system that can detect and track a ball correctly on any particular circumstances. Therefore, the system is created by using two methods. Circle Hough Transform method is used to detect a ball, while CAMSHIFT method is used to track the ball. Combining these two methods is very suitable with $100 \%$ accuracy. In its application, the object ball can be detected correctly even though it full, three-quarter, and the half part of the ball is visible. The farthest distance obtained robots to track the ball which reaches up to 900 $\mathrm{cm}$, with a processing time of approximately 0.1073 seconds.
\end{abstract}

Keywords: robot vision, circle hough transform, CAMSHIFT.

\section{Introduction}

Object tracking is one of the processes in determining the real objects or image using a computer system. The process of tracking can be performed directly using the external data [1]. External data sources that are received will be processed and converted into a digital data. The results of this data processing can be directly tracked the objects specified by color or shape. A lot of research that develops about robot vision, from industry to the world of Robotics [2]-[5]. To be able to identify targets and track, it takes the relevant approach method. One of the approaches is to utilize digital image processing. Tracking objects according to nature can be divided into three groups, namely: features, models and opticalflow [6].

Before formulating the tracking of objects, the most important operation is to identify the characteristics of an object. It can be any shape, color, texture, or size [7]. For example, detection of a luminous object distances can be overcome by using the method of moments [8]. This method is the basic method of Mean-Shift used to calculate area of an object on the track. The distance obtained through this method results in a less suitable distance value of $5.51 \%$ from the real distance. Other characters are in shape, which is to detect circle objects. There are many methods to detect circles, among others with the Circle Hough Transform (CHT) [9]-[11]. This method is especially helpful because of the tough characteristics. The results of the experiments experienced that this algorithm can detect the concentric circles of

ICCSET 2018, October 25-26, Kudus, Indonesia

Copyright $(9) 2018$ EAI

DOI 10.4108/eai.24-10-2018.2280634 
some forms of imagery that are incomplete and have a high efficiency in detecting circle shape [9].

In some cases, several analyzes were carried out combining two methods between feature extraction and object tracking. For example, the characteristics of SIFT and Mean-Shift used to track a picture object [6] or moveable objects (changeable) [12], and tracking objects with the merger of the two methods ASIFT and Mean-Shift, which in its analysis produced some important points where the value of accuracy achieved is 30\% to track objects [1]. Mean-Shift is a method that cannot adapt to significant changes. The CAMSHIFT algorithm is used to detect an adaptive object tracking. This method is an excellent tracking method to any object. It needs to be understood that this method is a modification of the Mean-Shift algorithm. In addition, there are many experiments on the accuracy of combining methods between Blob Detection with CAMSHIFT accuracy results were $96.6 \%$. It is compared to combine the CHT method with CAMSHIFT accurate results were $100 \%$ for a maximum distance of $500 \mathrm{~cm}$ [11].

From previous research, there has been no creation of a robot vision that can overcome ball detection and tracking quickly and precisely. The aim to be achieved is to optimize the incorporation of the CHT and CAMSHIFT methods in order to track the ball object up to a distance of $1000 \mathrm{~cm}$. The object tracking is applied to a robot vision in the process of detecting and tracking objects quickly and accurately. The robot vision is used to follow the movements of the moving ball.

\section{Research Methods}

\subsection{Object Detection with CHT Algorithm}

Circle Hough Transform (CHT) is one of the popular image processing algorithms in detecting objects that are round or circle. Basically, the CHT is the development of the Hough Transform [9]. One example is implemented by Hollit and Johnston to recognize detection feature in radio astronomy [13]. In its implementation, algorithm CHT perform mapping against the points on the image into the image parameters based on a function which defines a form which will be detected [14]. To detect circles by using the algorithm of the CHT, it takes some parameters that can be seen in Figure 2 [15].

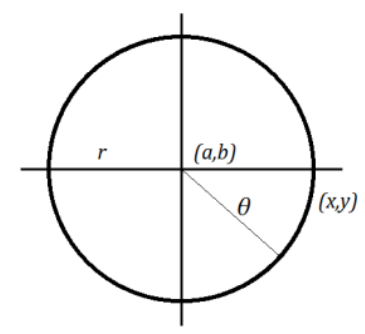

Fig. 1. Parameters to Detect Circles. 
On the circle has three parameters $r, a$, and $b$. Where $(a, b)$ is the center of the inner circle with $x$ and $y, r$ is the radius. Members of the circle parameters can be directly known at the edge of the circle with Equation 1 and 2 [9], [10], [14].

$$
\begin{aligned}
& x=a+r \cos \theta \\
& y=b+r \sin \theta
\end{aligned}
$$

where $(a, b)$ : the center point of the circle.

$(x, y):$ members of the pixels at the edge of the circle.

$r$ : radius on the circle.

This step can be obtained by the basic algorithm of Hough, with Canny edge detection techniques. It can be seen in Figure 3, searching the circle can be done on the space of perimeters by performing the accumulation of circles that are obtained.

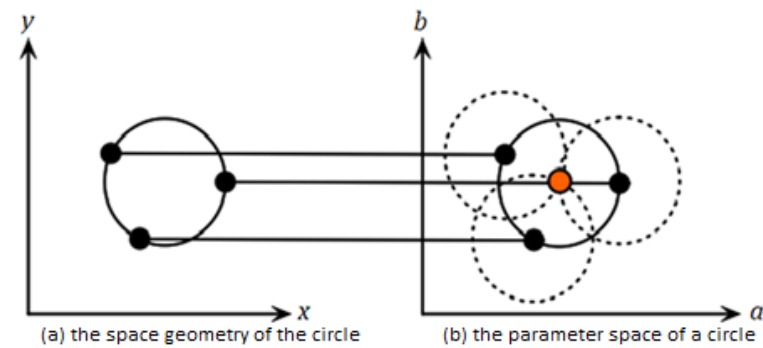

Fig. 2. Space Geometry and Space Perimeters of Circles.

\subsection{Object Tracking with CAMSHIFT Algorithm}

CAMSHIFT is the development of an algorithm of Mean-SHIFT [16]. This algorithm repeatedly performs adaptation to the probability distribution of the color-changing each video frame turnover [17]. This method is the next step after the detection of objects successfully conducted using CHT algorithmic. To conduct the process of tracking, this algorithm requires two values enter i.e. Value of HSV and starting positions of objects are located. Therefore, the result value of HSV and position objects that are retrieved to the algorithm CHT, directly fed into the search parameters on the CAMSHIFT. The parameters in the CAMSHIFT will conduct localizations shift calculation of midpoint (centroid) at each pixel is processed, as seen in Figure 4 [18].

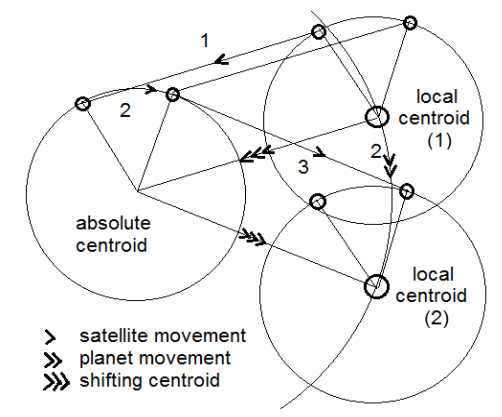


Fig. 3. Shifting The Midpoint of Object Pixels (Centroid).

The flowchart is created for processing this algorithm in Robot Vision as in Figure 5. This is a flow system that applied to Robot Vision, which enables the robot can recognize objects appropriately.

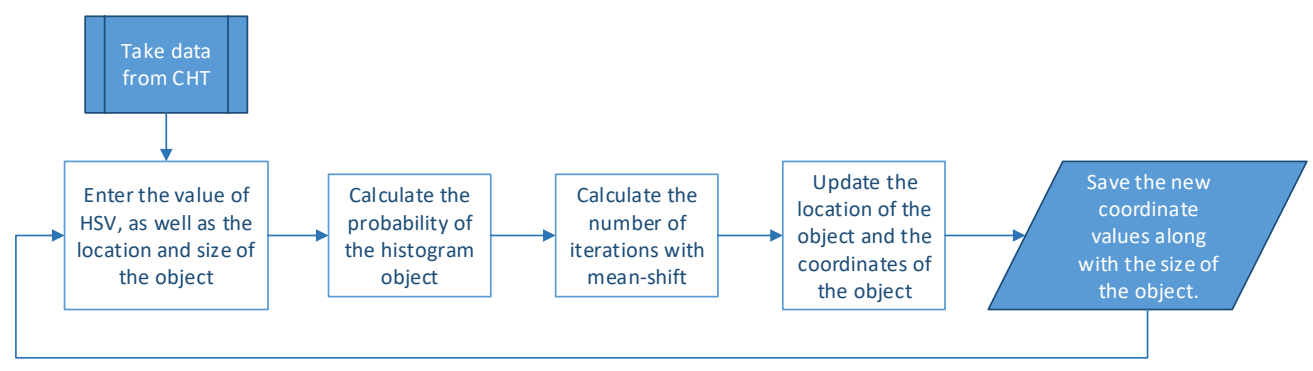

Fig. 4. Flowchart Object Tracking in Robot Vision.

\section{Results and Analysis}

The first experiment was to test the detection ball using CHT. Earlier, the first done setting limitations value HSV to do an orange color filter. It can be seen from Table 1, performed a few experiments with a set range of HSV as in Figure 5.

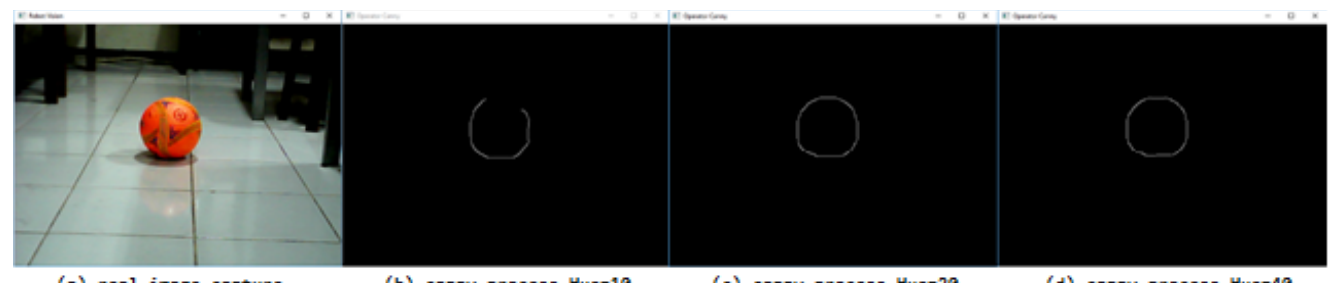

(a) real image capture

(b) canny process Hue $=10$

(c) canny process Hue $=20$

(d) canny process Hue $=48$

Fig. 5. Set Values of Hue Object.

Figure 5a is the image insert from the webcam and then processed to produce an image of Canny by Figure $5 \mathrm{~b}$ to $5 \mathrm{~d}$. The percentage of the results that are obtained by setting the value of the Hue can be seen in Table 1.

Table 1. Set value of HSV for processing

\begin{tabular}{ccccc}
\hline No. Image & Hue & $\begin{array}{c}\text { Set Range } \\
\text { Satur. }\end{array}$ & $\begin{array}{c}\text { Edge } \\
\text { Value }\end{array}$ & Detection \\
\hline Figure 6(b) & $0-10$ & $103-255$ & $90-255$ & $80 \%$ \\
Figure 7(a) & $0-20$ & $103-255$ & $90-255$ & $100 \%$
\end{tabular}


By setting the HSV has been set, it is obtained good detection results to detect the object ball. In Figure 6, the obtained results are full of the circular edge detection. These lines will do accumulation calculations for the determined line that the circle formed is the object sought.

Now it will try for a different background than ever. There are the results obtained by processing as in Figure 7.

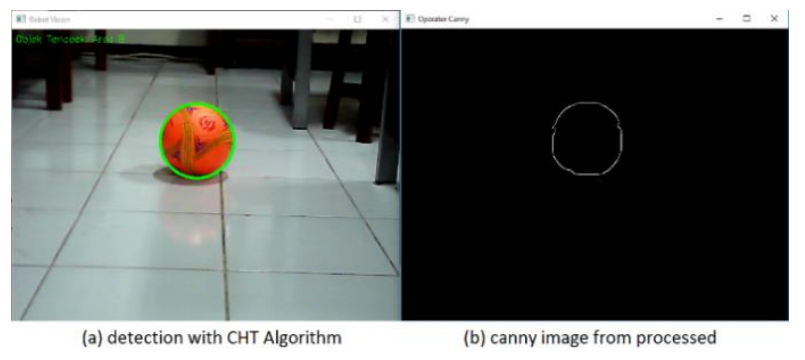

Fig. 6. A Ball Detection with Full Edge.

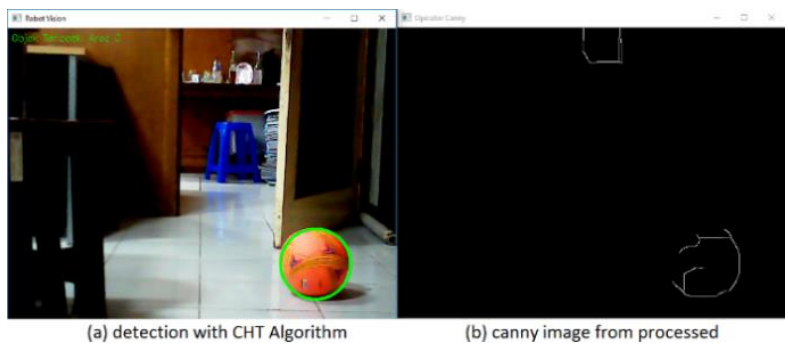

Fig. 7. A Ball Detection with Half Edge.

It can be seen from Figure 6 and Figure 7, the algorithm CHT can read the line edge that is not intact most of at least half of the circle. The robot can detect the position (location) of the object coordinates correctly.

In the second experiment, the data are obtained from the algorithm CHT i.e. value of HSV and point the location at an object. Then, the data are fed into the calculation parameters CAMSHIFT. Prior to the iteration calculation, first made the histogram on the location object is detected on the original image as in Figure 8.

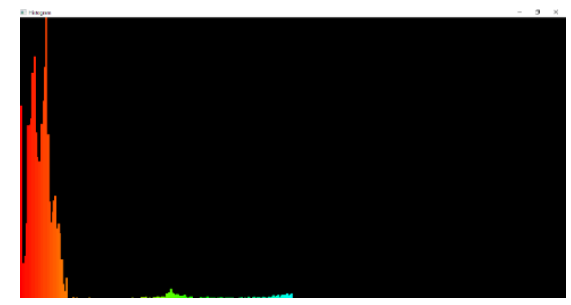


Fig. 8. The Histogram of The Ball.

To perform object tracking with CAMSHIFT, pseudocode can be used as below.

For image (src, center, radius)

imgROI = image.size (), center, radius; // setROI image

Dilate -> image; $\quad$ // fill hole image

RotateRec track $=$ Camshift $(\mathrm{src}$, imgROI);// Tracking object

return image

Histogram calculation results that are sought made the image circle reposition the object being tracked. By applying the pseudocode at above, this method can do tracking on the object search based on a histogram of such objects as in Figure 9.

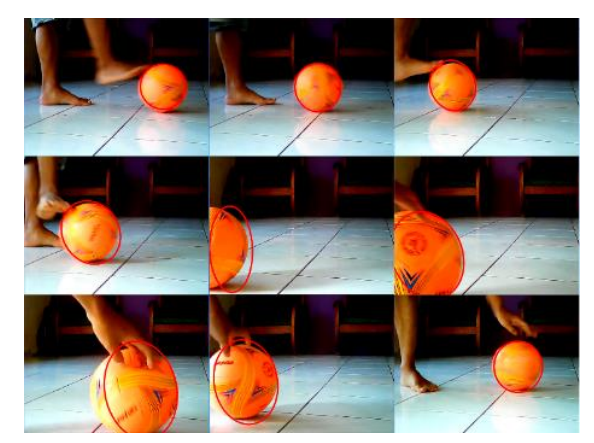

Fig. 9. Tracking Object with CAMSHIFT Algorithm.

In Figure 9, the ball can be tracked by performing iterations of the histogram that is already determined. The movement of the objects can be tracked perfectly and regularly performing a histogram adaptation happens at the ball. When the ball was exposed to excessive light, the histogram will change and will also change the calculation of the position on the object. It happens as well when the object does not fully enter the tracking frame, so only half of the object being tracked by robots.

The experiment is done again to find out how far a distance which can be reached by this method. The distance is tested starting from $100 \mathrm{~cm}$ up to $900 \mathrm{~cm}$, the results of this test can be seen in Table 2.

Table 2. Distances Tracking of The Ball.

\begin{tabular}{cccc}
\hline No. Image & Distance & Result Tracking & Time Process (s) \\
\hline Frame-1 & $100 \mathrm{~cm}$ & OK & 0.0977 \\
Frame-2 & $200 \mathrm{~cm}$ & OK & 0.0978 \\
Frame-3 & $300 \mathrm{~cm}$ & OK & 0.1120 \\
Frame-4 & $400 \mathrm{~cm}$ & OK & 0.1056 \\
Frame-5 & $500 \mathrm{~cm}$ & OK & 0.1099 \\
Frame-6 & $600 \mathrm{~cm}$ & OK & 0.0900 \\
Frame-7 & $700 \mathrm{~cm}$ & OK & 0.1000
\end{tabular}




\begin{tabular}{cccc} 
Frame- 8 & $800 \mathrm{~cm}$ & OK & 0.1266 \\
Frame-9 & $900 \mathrm{~cm}$ & OK & 0.1162 \\
Averages Success Track & $100 \%$ & 0.1073 \\
\hline
\end{tabular}

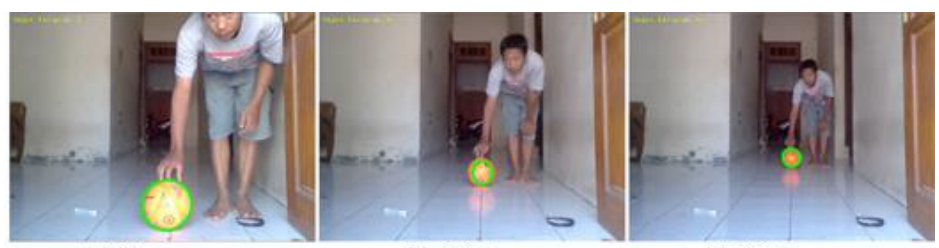

(a) $100 \mathrm{~cm}$

(b) $200 \mathrm{~cm}$

(c) $300 \mathrm{~cm}$
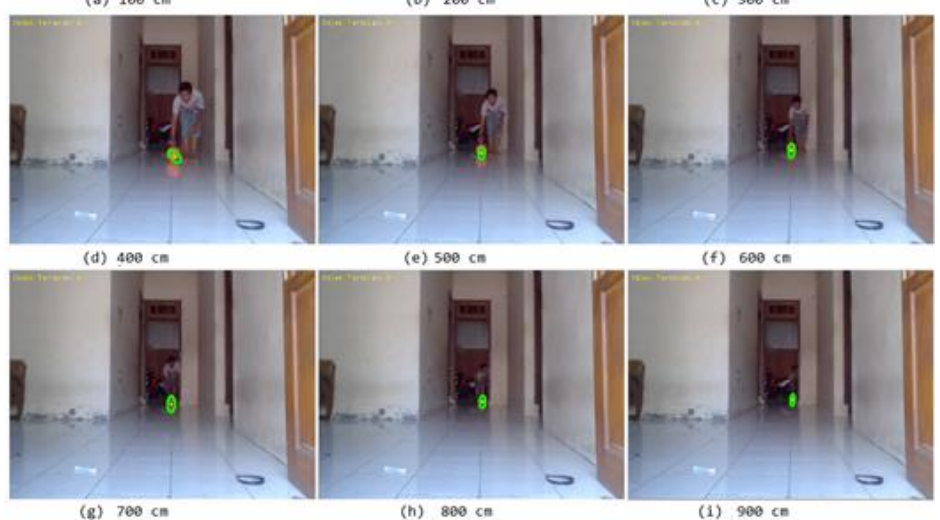

(g) $700 \mathrm{~cm}$

(h) $800 \mathrm{~cm}$

(i) $900 \mathrm{~cm}$

Fig. 10. Experiment with Different Distance.

It can be seen from the Figure that the farthest distance obtained robots to track the ball which reaches up to $900 \mathrm{~cm}$, with a processing time of approximately 0.1073 seconds. So, the robot reaches the blind spot in the numbers.

\section{Conclusions}

Robot Vision that is created by using the merge of two methods has its own advantages. The robot can detect and track objects that are specified precisely. There are some constraints when the object is more than $900 \mathrm{~cm}$, i.e. the robot cannot recognize and track the object. So the robot will stop in the distance. Time which is taken to track the objects is also relatively fast namely 0.1073 seconds. Although at the time of the identification of the object with the algorithm CHT takes a relatively long time, but it will not affect the CAMSHIFT algorithm to track the object quickly. It is because the method of CHT is only done once when making the identification of the object. It can be concluded that this method can overcome the robot in identifying and tracking objects with precise and fast. For the future, this method could be developed further by embedding expert system to recognize some of the ball, where the ball should be tracked and which are not. 


\section{References}

[1] A. Wijayana, T. A. B. W, and S. Sa'adah, "Analisis dan Implementasi Object Tracking Menggunakan Metode ASIFT dan Mean Shift," in e-Proceeding of Engineering, 2015, vol. 2, no. 1, pp. 1166-1176.

[2] A. Owen-Hill, "Robot Vision vs Computer Vision: What's the Difference?," Robotiq, 2016. [Online]. Available: https://blog.robotiq.com/robot-vision-vs-computer-vision-whats-the-difference. [Accessed: 25-Feb-2018].

[3] T. G. Sanchez, "Artificial Vision in the Nao Humanoid Robot," 2009.

[4] L. Wang, B. Schmidt, and A. Y. C. Nee, "Vision-guided active collision avoidance for humanrobot collaborations," Manuf. Lett., vol. 1, no. 1, pp. 5-8, 2013.

[5] S. Y. Chen, "Kalman filter for robot vision: A survey," IEEE Trans. Ind. Electron., vol. 59, no. 11, pp. 4409-4420, 2012.

[6] H. Zhou, Y. Yuan, and C. Shi, "Object tracking using SIFT features and mean shift," Comput. Vis. Image Underst., vol. 113, no. 3, pp. 345-352, 2009.

[7] A. Kadir and A. Susanto, Teori dan Aplikasi Pengolahan Citra, 1st ed. Yogjakarta: ANDI, 2013.

[8] R. O. Wiyagi and M. Y. Mustar, "Deteksi Jarak Objek Bercahaya Secara Real Time Menggunakan Kamera Tunggal," in 3rd Indonesian Symposium on Robot Soccer Competition, 2015, no. June 11 th.

[9] X. Chen, L. Lu, and Y. Gao, "A new concentric circle detection method based on Hough transform," in ICCSE 2012 - Proceedings of 2012 7th International Conference on Computer Science and Education, 2012, pp. 753-758.

[10] A. O. Djekoune, K. Messaoudi, and K. Amara, "Incremental circle hough transform: An improved method for circle detection," Optik (Stuttg)., vol. 133, pp. 17-31, 2017.

[11] E. M. Pamungkas, B. A. A. Sumbodo, and I. Candradewi, "Sistem Pendeteksi dan Pelacakan Bola dengan Metode Hough Circle Transform , Blob Detection , dan Camshift Menggunakan AR.Drone," vol. 7, no. 1, pp. 1-12, 2017.

[12] D. Comaniciu, V. Ramesh, and P. Meer, "Real-time tracking of non-rigid objects using mean shift," Proc. IEEE Conf. Comput. Vis. Pattern Recognition. CVPR 2000 (Cat. No.PR00662), vol. 2, no. 7, pp. 142-149, 2000.

[13] C. Hollitt and M. Johnston-Hollitt, "Feature detection in radio astronomy using the circle hough transform," Publ. Astron. Soc. Aust., vol. 29, no. 3, pp. 309-317, 2012.

[14] A. H. Halimatus Sa'diyah , R.Rizal Isnanto, "Penggunaan Algoritma Hough Tranforms Untuk Deteksi Bentuk Lingkaran pada Ruang 2D," pp. 2-5, 2010.

[15]"Library Binus," Universitas Bina Nusantara. [Online]. Available: http://library.binus.ac.id/eColls/eThesisdoc/Bab2HTML/2009200427SKBab2/body.html. [Accessed: 22-May-2018].

[16] J. G. Prayugo, "Pendeteksian Wajah dengan Algoritma camshift," Universitas Sanata Dharma, 2010.

[17] Sultoni, "MODIFIKASI METODE CAMSHIFT UNTUK PENGENALAN CITRA WAJAH SECARA REAL TIME BERDASARKAN WARNA KULIT," Semin. Nas. Inov. dan Apl. Teknol. di Ind. 2017, pp. 1-7, 2017.

[18] T. Darmanto, I. S. Suwardi, and R. Munir, "Orbital trajectory simulation of satellite around space object by fractal animation model based on shifting centroid from a fixed point," Konf. Nas. Inform. 2013, no. October, 2013. 